\title{
ESTILOS C
}

DOI: https://doi.org/10.11606/issn.1981-1624.v24i2p304-316.

\section{Artigo}

\section{Entre ter uma deficiência e ser deficiente: um estudo sobre as identificações*}

\author{
Diego Rodrigues Silva; Eliana Herzberg
}

Resumo. Diversos trabalhos consideram que pessoas com deficiência física possuem sentimentos de inadequação, inferioridade e baixa autoestima. Parte-se da narrativa de Sunaura Taylor para localizar a questão no paradigma ver/ser visto para problematizar o tema. Assim, tem-se por objetivo discutir os efeitos imaginários da identificação nestes casos. De Freud à Lacan o conceito de narcisismo remete à formação do eu, bem como os processos de identificação a imagens e palavras advindas do Outro. Das imagens e sentidos atribuídos à deficiência pelo social encontram-se descritos na literatura as concepções de estranho e incapaz, da deficiência como doença ou castigo e referências a seres fantástico. Deste modo, foi proposto que pessoas com deficiência possam assumir o lugar de "deficiente" e seus respectivos sentidos por meio da identificação. Concluiu-se que os sentimentos de inadequação perpassam a dimensão imaginária de se ver sendo visto como "deficiente". Dada esta função de representação para o Outro e unificação do eu, tratam-se de momentos em que se deixa de ter uma deficiência para sê-la, enquanto uma forma que lhe dá sentido e o organiza, ainda que possa trazer sofrimento

Palavras-chave: deficiente físico; narcisismo; autoconceito.

\section{Entre tener una deficiencia y ser deficiente: un estudio sobre las identificaciones}

Resumen. La literatura considera que las personas con deficiencia física tienen sentimientos de inadecuación, inferioridad y baja autoestima. Con la narrativa de Sunaura Taylor, fue localizar la cuestión en el paradigma ver/ser visto para problematizar. Su objetivo es discutir los efectos imaginarios de la identificación en estos casos. De Freud a Lacan el concepto de narcisismo se refiere a la formación del ego, así como a los procesos de identificación con imágenes y palabras del Otro. De él se atribuye a la deficiencia por las concepciones sociales de extrañas e incapaces, como enfermedad o castigo y referencias a seres fantásticos. Se propuso que los sujetos

*Apoio: Coordenação de Aperfeiçoamento de Pessoal de Nível Superior - Brasil (Capes) Código de Financiamento 001

1. Psicanalista. Doutorando do Instituto de Psicologia da Universidade de São Paulo, São Paulo, SP, Brasil. Email: silva.diego@usp.br

2. Professora e pesquisadora do Departamento de Psicologia Clínica do Instituto de Psicologia da Universidade de São Paulo, São Paulo, SP, Brasil. E-mail: eherzber@usp.br 
con discapacidad puedan asumir el lugar de la "deficiencia" y sus sentidos respectivos a través de la identificación. Se concluyó que los sentimientos de inadecuación impregnan la dimensión imaginaria de ser vistos como "deficiencia". Dada esta función de representación para el Otro y la unificación del ego, son momentos en los que uno deja de tener una deficiencia para ser uno, como una forma que le da sentido y lo organiza, aunque pueda traer sufrimiento.

Palabras-clave: deficiente físico; narcisismo; autoimagen.

\title{
Between have a disability and being disabled: a study on identifications
}

\begin{abstract}
Studies consider that people with physical disabilities have feelings of inadequacy, inferiority and low self-esteem. Following from the Sunaura Taylor's narrative, it was located the matter on the see/to be seen paradigm to problematize. Thus, it aims to discuss the imaginary effects of identification in these cases. From Freud to Lacan, the concept of narcissism refers to the formation of the ego, as well as the processes of identification to images and words from the Other. From the perception and meaning attributed to disability by the social conception found on the literature as strange, an inability, disease, punishment and references to fantastic beings. Therefore, it was proposed that subjects with disabilities can assume the place of "disabled" and their respective senses through identification. In conclusion, the feeling of inadequacy intersects the imaginary dimension of being seen as "disabled". Given this function of representation for the Other and unification of the ego, these are moments in which one ceases from having a disability to becoming one, as a form that gives it meaning and organizes it, even if it causes suffering.
\end{abstract}

Keywords: physically disabled; narcissism; self concept.

No documentário Examined Life dedicado à Judith Butler (Taylor, 2008), é retratado seu diálogo com Sunaura Taylor, pintora e ativista americana cadeirante devido à deficiência física ocasionada por antrogipose congênita, doença que ocasiona contraturas nas articulações, podendo deixar curvos os membros. No diálogo, Butler lhe pergunta se sente-se livre, capaz de se mover das formas que quer. Taylor responde: "Eu posso entrar num café e pegar o copo com a minha boca e levá-lo até à minha mesa. Mas isso... Isso torna-se mais difícil por causa dos padrões de normalização dos nossos movimentos". "E o desconforto que isso causa... quando faço coisas com partes do corpo que não servem necessariamente para aquilo que assumimos que servem, isso parece ser muito dificil para as pessoas". E detalha da infância: "quando ainda caminhava, e me era dito que caminhava como um macaco".

Nesta linha, a literatura tem explorado a associação entre deficiência física e sofrimento. Diversos trabalhos (Taleporos \& McCabe, 2002; Tam, Chan, Lam, \& Lam, 2003; Shields, Murdoch, Loy, Dodd \& Taylor, 2006; Sit, Lau \& Vertinsky, 2009; Gascón, Santos, Capitão, Fantine-Nogueira \& Oliveira, 2013; Suc, Lesnik \& Erpic, 2015) apontam para uma maior incidência de sentimentos de inadequação, inferioridade e baixa autoestima em pessoas com deficiência física. A principal causa associada é a discriminação social, uma vez que a aparência alterada da deficiência é incompatível com os padrões esperados. $\mathrm{Na}$ proposta destes trabalhos, o olhar de estranhamento sobre a deficiência ou mesmo a distância que estes se encontram dos ideais acarretariam em tais sentimentos.

Primeiramente, é preciso esclarecer que "maior incidência" não significa uma ocorrência obrigatória. Deste modo, este trabalho se deterá na parte dos casos em que isto ocorre e pode demandar um trabalho clínico. Como será exposto, a proposta é percorrer um caminho pela singularidade em que todos os arranjos são possíveis e, ao final, esperamos que esta advertência já se torne obsoleta. 
Segundo Amaral (1998), enquanto inseridos na classe de seres humanos, todos compartilham de uma vocação para determinadas formas e funções. São pressupostas determinadas peculiaridades anatômicas e funcionais, como a presença de dois olhos no topo da cabeça que enxerguem e membros que permitam ações como andar e manipular objetos. “Qualquer alteração de maior monta nesta 'vocação' caracteriza a pessoa que vive essa condição como significativamente diferente, desviante, anormal e com deficiência” (p. 14). A partir desta definição, nossa leitura da fala de Sunaura Taylor parece retratar uma dificuldade colocada pela deficiência. De um lado tem-se a sensação de estranhamento ao ver um corpo "diferente" sendo utilizado de formas não usuais por aquele que não possui uma deficiência. De outro, há a experiência de ser visto como "diferente". Em ambos se evidencia o jogo imaginário de modelos, o ordenamento sobre o que é um corpo, como se deve executar cada movimento e como se portar. Assim, enfatizando a perspectiva da pessoa com deficiência, o que ocorre ao ser visto como diferente? Poderia este olhar trazer prejuízos para o narcisismo? Longe de respostas objetivas, as questões incitam uma discussão sobre o olhar e ser olhado e seus efeitos imaginários. Podemos partir de que não se trata de um simples desconforto causal direto advindo de um olhar desqualificante, como indica Lacan (1960-61/1992):

É, realmente, a mais simples das hipóteses, supor o Outro um espelho vivo, de tal modo que, quando olho pra ele, é ele em mim quem se olha e quem se vê em meu lugar, no lugar que ocupo nele. Se ele nada mais é que seu próprio olhar, é ele quem funda o verdadeiro desse olhar (p. 362).

É preciso adentrar aos lugares supostos à deficiência e como este fornecem significados que permitem assumir possíveis posições inferiorizantes e sensações de desconforto acerca de si e do próprio corpo. Este, longe de ser um produto natural, é marcado por estes lugares, produzindo algo novo, dado o "pouco acesso que o sujeito tem à realidade deste corpo, perdida por ele em seu interior, no limite em que redobra de camadas coalescentes a seu invólucro, ele o imagina como uma luva que pode ser virada pelo avesso" (Lacan, 1960/1998c, p. 682). Deste modo, levantamos ainda os efeitos deste olhar inclusive sobre o corpo e seus movimentos.

Isto posto, o artigo tem por objeto discutir os efeitos imaginários da identificação nos casos de deficiência física. A discussão permite analisar a questão para além da noção de preconceito e investiga os efeitos do olhar para o corpo e sua imagem quando há uma deficiência. O exemplo de Taylor se coloca como um guia de reflexão, um fenômeno a ser analisado. Deste modo, não se trata de tecer uma interpretação, mas de discutir teoricamente a estrutura clínica do fenômeno para se pensar outros casos de pessoas com deficiência.

\section{O "ser olhado" e o narcisismo: Freud}

Olhar e ser visto compreende uma dialética imaginária importante em que se colocam em cena as dinâmicas do investimento narcísico e objetal e seus desdobramentos. Trata-se de um percurso que se inicia no narcisismo desde o investimento parental e culmina na construção da imagem de si, uma imagem do corpo que organiza e impõe um ideal. Freud em 1905 (1996a) inicia seu trabalho acerca do narcisismo discutindo o fenômeno do tomar a si como objeto sexual na homossexualidade, o que até então fora visto apenas enquanto um funcionamento patológico. Já neste texto pontua que há, na base deste funcionamento, o 
mecanismo de identificação. Em 1910 (1996b), o autor avança remontando o narcisismo a um amor vindo da infância, de modo que o sujeito ama tal como fora amado por seus pais, sendo algo pertencente ao desenvolvimento de todos. Com Schereber, Freud (1911/2010) detalha que, enquanto um período do desenvolvimento, o narcisismo está entre a fase auto erótica e a do amor objetal, de modo que seus efeitos permanecem ao longo da vida. Como afirma:

o indivíduo em desenvolvimento, que unificou seus instintos sexuais que agem de forma autoerótica, a fim de obter um objeto de amor, primeiramente toma a si mesmo, a seu próprio corpo, como objeto de amor, antes de passar à escolha de uma outra pessoa como objeto (p. 81).

Trata-se de uma organização em que se reúnem as pulsões para investir em um primeiro objeto, "seu próprio ego, que se constituiu aproximadamente nesta mesma época" (Freud, 1912-13/1996c, p. 102). Como característica do narcisismo ressalta a supervalorização do pensamento, sendo esta fase "a origem de sua fé na onipotência dos pensamentos, de sua inabalável confiança na possibilidade de controlar o mundo e de sua inacessibilidade às experiências, tão facilmente obteníveis, que poderiam ensinar-lhe a verdadeira posição do homem no universo" (Freud, 1912-13/1996c, p. 102).

Desde este ponto, mostra como a partir do investimento de si, o sujeito investe os objetos, atribuindo um sentido unívoco sobre ambos. Assim como, em uma nota deste texto, Freud (1912-13/1996c) aponta para o sentimento de inferioridade, que, para ele, advém do narcisismo original das crianças. Cabe citar, quanto a este ponto, uma ressalva mais adiante em sua obra, na leitura da biografia de um homem com deficiência física. Em sua leitura, discute que após o nascimento, sua mãe "retirou do filho o seu amor, por causa da enfermidade dele" (1932/1996g, p. 71). Relaciona assim, a falta de um investimento nessa etapa primordial e a ocorrência de uma forma de se colocar frente ao outro de forma inferiorizada. Nestas duas vertentes, marca-se como o olhar sobre si constrói sentidos e compõe o modo como cada sujeito se organiza frente ao outro e o que pode ocorrer quando há uma deficiência que altera a imagem que se dá a ver ao outro.

Em 1914 (1996d), Freud diferencia libido objetal de libido do ego, de modo que a primeira deriva da segunda na medida em que é empreendida em objetos externos. Há uma relação quantitativa, aponta, em que quanto mais uma é empregada mais a outra é esvaziada. Acrescenta ainda que os primeiros objetos investidos pelos sujeitos são as pessoas que se ocupam com seus cuidados essenciais, sendo este o modelo anaclítico, ou de ligação, que diferencia do modelo narcísico que o objeto investido é o eu. Sem esquecer que este eu, em seu rudimento, é um eu corporal, a projeção de sua superfície (Freud, 1923/1996f). Trata-se de um investimento no corpo quando ainda não se tem um eu constituído, ou pelo menos de uma imagem deste corpo.

Distinguindo a escolha de objeto narcísica e anaclítica, Freud (1914/1996d) indica que no primeiro as escolhas podem seguir o modelo de quem se é de fato, quem se foi e quem gostaria de ser. No segundo, coloca a mulher que o alimenta e o homem o protege, organizando assim os modos pelo qual a economia libidinal se orienta. Esta, por sua vez, também passa a se organizar pelos ideais culturais ao longo do desenvolvimento, fontes do recalque, marcando um padrão a ser seguido pelo eu, levando a algumas perdas narcísicas. $\mathrm{O}$ que insere aqui é a noção de ideal, "um ideal em si mesmo, pelo qual mede seu ego real" (p. 100, grifo do autor). Este eu ideal remonta ao "amar como fora amado", no sentido de que a imagem daquele que se foi, enquanto foi amado, investido libidinalmente por seus pais com 
“toda perfeição de valor" (p. 100). Este estado narcísico perdido da infância, se fixa como uma imagem ideal nunca renunciada e buscada ao longo da vida. Este ideal, atuando como um vigia, diz Freud, surge da influência crítica dos pais, que o transmite pela voz, pelos educadores, pessoas do ambiente e a opinião pública.

Mais uma vez se insere a questão da doença orgânica na discussão. Freud (1914/1996d) afirma que um mal-estar orgânico promove o movimento de retirada da libido do mundo externo, diminuindo seu interesse: "enquanto sofre, deixa de amar" (p. 89). Ilustra assim como o narcisismo pode modificar as catexias sobre o corpo, que por sua vez incidem na catexia libidinal do eu. A autoestima é retomada neste texto, sendo dimensionada por este investimento no eu. Se Freud havia dito sobre as primeiras experiências com os pais, acrescenta aqui as experiências de possibilidade de satisfação do ideal de eu e de satisfação libidinal com os objetos para a determinação da autoestima. Deste modo, a relaciona a ser amado (investido pelo desejo do outro), enquanto a possibilidade de ser reconhecido enquanto mimetizando seu ideal e se satisfazendo com os objetos. Adiante, em 1920 (1996e), o autor generaliza a inferioridade, dizendo ser algo próprio do neurótico que, por uma incompatibilidade de sua fantasia com a realidade, perde seu lugar de investimento ideal. De maneira interessante e análoga, Lacan (1960-61/1992) cita que um melancólico que se inferioriza não o faz por se achar feio, mas por não investir em seu ideal, não encontrar traços de identificação para se satisfazer. "Reparem que não se trata nunca da imagem especular. $\mathrm{O}$ melancólico não diz a vocês que ele tem má aparência, ou uma cara feia, ou que é corcunda, mas sim que é o último dos últimos" (p. 380).

\section{O "ver" e a identificação: Lacan}

A retomada de Lacan sobre os textos freudianos apresentados recoloca o conceito de narcisismo articulando-o entre corpo, o investimento narcísico, a identificação e o modo como estes circulam em torno dos ideais. No "Estádio do Espelho", Lacan (1949/1998b) postula o surgimento do eu em uma relação especular da criança com o outro. Usa a metáfora do espelho para indicar que um bebê, aos seis meses, começa a se reconhecer no espelho, ou seja, ao ver a figura se mover junto consigo, se identifica à imagem virtual. Há uma antecipação, visto que é suposta uma imagem completa onde não havia ainda tal organização. Esta identificação, indica o autor, se faz importante mesmo para sua motricidade, que passa a se ordenar com um contorno humano. O foco recai sobre como a imagem de um Outro semelhante é constitutiva para o eu, ainda que o aliene a esta imagem, enquanto uma forma única de se fazer representar. Esta imagem é compreendida por Lacan como eu-ideal, investido pelo narcisismo, em referência aos textos de Freud, sendo sua identificação uma primeira organização na linha de uma ficção organizadora, antes mesmo da incidência das determinações sociais.

Tem-se assim, a partir da experiência/metáfora do espelho, que o sujeito se identifica à imagem do outro e que tal identificação promove uma mudança, sendo esta a base para as mudanças posteriores, de modo que possa se afirmar como "Eu sou humano", "Eu sou brasileiro" e todas as consequências imaginárias destas definições. Ainda que haja uma confusão entre o eu e o sujeito do inconsciente, lugar em que escapam todos os predicativos (Lacan, 1948/1998a). 
Utilizou-se os termos "experiência" e "metáfora", no sentido em que o contato com o espelho para a criança promove uma identificação, mas é enquanto metáfora do que se passa na relação que o estádio do espelho tem sua maior contribuição. O mesmo será repetido em 1953-54 (1986), quando Lacan trabalha de modo mais complexo valendo-se do experimento do vaso invertido, em que o jogo de espelhos diz do modo com que o sujeito se identifica à (sua) imagem. A conceito de imagem é fundamental, visto que nesta leitura a proposta de Freud de investimento nos objetos não se dá com os objetos de fato, mas com suas imagens. Estas advêm, para Lacan (1953-54/1986), da primeira imagem fundamental:

Há inicialmente, com efeito, um narcisismo que se relaciona à imagem corporal. Essa imagem é idêntica para o conjunto dos mecanismos do sujeito e dá sua forma ao seu Umwelt, na medida em que é homem e não cavalo. Ela faz a unidade do sujeito, e nós a vemos se projetar de mil maneiras (p. 147 - grifo do autor).

Assim, é pela imagem que constrói quadros pré-formados da realidade que visam fixar um traço comum para o que é diverso. Tal como visto em Freud, da forma como se é olhado, constroem-se formas de olhar o mundo. No entanto, tratam-se de formas unívocas, estanques, definidas.

Acerca do experimento, comenta que é possível ver um vaso envolver um buque de flores, ainda que o vaso não esteja onde parece estar. Por meio de um espelho côncavo, a depender de onde se olha, o vaso, invertido embaixo da mesa, se mostra do lado de cima no reflexo, acolhendo as flores. Pelas leis da ótica, linhas traçam o percurso da imagem para o reflexo, passando por um ponto de foco que permite que o vaso invertido seja projetado em uma imagem real em cima da mesa. Colocando um espelho plano a frente, o observador veria por este uma imagem virtual da composição completa. Nestes termos, o estádio do espelho é relido enquanto metáfora da formação do eu na relação com o outro semelhante. Onde não havia nada, surge um eu, a imagem real do vaso. Logo, se dá um malogro, dado que o vaso visto é um truque de espelhos, um produto da relação: não é uma consistência definitiva. $O$ espelho plano é o outro, à figura parental para onde olha a criança a fim de confirmar se a imagem no espelho lhe corresponde. Assim, é no espelho, no outro, que se formará a imagem com que o sujeito se identifica, contudo, para tanto dependerá o angulo em que se olha, mais uma vez mostrando a inconsistência do eu e as condições para sua existência (Lacan, 1953/1986; 1960/1998c; 1960-61/1992).

Algumas consequências se apreendem desta analogia. Da imagem que se organiza no espelho, Lacan (1953/1986) indica ser o eu ideal. Trata-se da identificação à imagem que vem do outro, que se produziu no outro. Nos termos de Freud, a majestade o bebê, aos olhos dos pais produz uma imagem ideal, imagem que, se assumida, poderia fazer recuperar o investimento perdido. É desta forma que a identificação com a imagem impõe uma forma de se posicionar.

Freud em 1914, utiliza em um momento eu ideal e ideal de eu, lançando uma problemática retomada por Lacan, cuja discussão vem discriminar o que está no texto original. Distingue assim, que o primeiro está no plano imaginário e o segundo no simbólico, abarcando as exigências da lei (1953/1986); “o Ideal do Eu, seguindo a lei de agradar, leva o sujeito a se desagradar ao sabor da ordem; o Eu Ideal, com o risco de desagradar, só triunfa ao agradar a despeito da ordem" (1960/1998c, p. 678). Assim, indica o Ideal de Eu como um modelo e o Eu Ideal como aspiração; do ponto de vista da experiência do vaso, a imagem real formada é o eu ideal, grafado por $i(a)$ e o foco por onde convergem os raios dos reflexos para formar a 
imagem o ideal de eu, grafado por $I$. Com isso, o eu ideal é a imagem engendrada pelo desejo do outro, como visto, e o ideal de eu é um organizador, a presença de uma lei que ordena o desejo do sujeito (1960-61/1992; 1961-1962/2003). A relação entre ambos se dá na medida em que o ideal de eu permite manter, de alguma forma, o eu ideal. Como exemplo, cita (196061/1992) o rapaz em seu carro esporte e a mulher que decide entrar para o partido comunista. Em ambos está em jogo sustentar uma posição, mimetizar um ideal. Porém, ambos dependem da figura do pai, de modo que o rapaz considera ser "comportado, de boa família" e a mulher entende seu ato como uma afronta ao pai. Em ambos, a forma de satisfazer o ideal de eu, tentar restituir o lugar de investimento do outro, perpassa um ordenamento, no caso, agradar, ou desagradar o pai.

Quando se diz que ideal de eu e eu ideal articulam imaginário e simbólico, isto ocorre devido a um detalhamento a respeito do outro, o espelho plano. Lacan (1960-61/1992) marca esse com maiúscula, Outro, enquanto instância doadora de sentidos, um lugar de referência para o pequeno sujeito encarnado no cuidador:

O eu só se apresenta e se sustenta, como problemático, a partir do olhar do grande Outro. O fato de que este olhar seja interiorizado por sua vez não quer dizer que ele se confunda com o lugar e o suporte que já estão constituídos como eu ideal (p. 342-343).

Desta forma, Lacan detalha que a identificação da relação narcísica com o Outro, se dá por um traço, um signo: o traço unário. Tal traço, também associado à grafia $I$, ideal de eu, regula o jogo dos espelhos/identificações. Trata-se da forma pela qual o sujeito pode sair do ideal imaginário do campo narcísico e se identificar à um traço articulável, ainda que em referência a este. Observa-se a articulação do simbólico com o imaginário, que se estende ao ponto que Lacan (1960-61/1992;1961-1962/2003) recupera a falta no esquema, na medida que, marcado pelo traço unário, se inscreve a linguagem e, delimitando contornos, deixa algo de fora, o que escapa às significações, o objeto $a$. Na articulação com a experiência do vaso invertido, associa $a$ às flores, na medida que o vaso, $i(a)$, vem justamente envolvê-las. Como consequência, tem-se a fórmula: o eu ideal, contornando $a$, organiza a fantasia, que por sua vez é suporte do desejo. Ou seja, é evidenciado de que modo o sujeito se organiza a partir da imagem do Outro e como seus desejos são regulados, dado que ideal de eu e eu ideal operam em conjunto. Um interessante exemplo é dado para falar do altruísmo. O autor cita aquele que ajuda "uma pobre menina", tomada enquanto tal pelo sujeito que ajuda. Em i(a) surge a angústia, montando a cena em que o sujeito, mimetizando o altruísta, supõe na menina um estado tal que em sua fantasia possa operar. Na menina se encontra o objeto $a$, e ali seu desejo contorna e engendra a cena em que o sujeito se considera estar ajudando. Assim, na medida em que algo falta, $a$ concebe o brilho aos objetos, causando para o $i(a)$ o desejo de investi-los narcisicamente seguindo a ficção da fantasia.

Esta retomada conceitual vem estabelecer alguns marcos teóricos importantes para se discutir o desconforto acerca da pessoa com deficiência se ver sendo vista enquanto tal. E assim, como pode se identificar a esta imagem, se transformar a partir dela. Este movimento remonta aos primeiros anos, em que andar "como um macaco" pode incitar traços e marcar posições. Como visto em Freud e Lacan, tal imagem de si é base para a construção da imagem dos objetos, de como organiza sua realidade e nela se posiciona.

\section{Os ideais e seus efeitos}


Se a literatura sustenta a ocorrência de sentimentos de inadequação das pessoas com deficiência, recuperamos que Freud (1932/1996g) mesmo já o propunha no estudo da biografia citado. Acompanhando sua obra, o conceito de narcisismo frequentemente aparece atrelado à questão da inferioridade. Em 1913 (1996d), em uma nota afirma que "o narcisismo original das crianças tem uma influência decisiva sobre nossa visão de desenvolvimento de seu caráter e exclui a possibilidade de terem elas qualquer sensação primária de inferioridade" (p. 103). Em 1914 (1996d) afirma que a autoestima expressa o tamanho do ego. "tudo o que uma pessoa possui ou realiza, todo remanescente do sentimento primitivo de onipotência que sua experiência tenha confirmado, ajuda-a a aumentar sua autoestima" (p. 104). Assim, compreende que uma parte da autoestima é primária, advinda da vivencia infantil, a segunda advém da experiência e suas possibilidades de realização do ideal do eu e a terceira da satisfação libidinal-objetal. A autoestima se encontra dependente da libido narcisista e a "finalidade e satisfação em uma escolha objetal narcisista consiste em ser amado" (p. 105), logo, objeto de investimento libidinal do outro. Nos casos de inferioridade, cita que pacientes que sofrem de neurose de transferência, encontra como causa o empobrecimento do eu, dada a libido retirada de si sem que haja a contrapartida de investimento necessária para manter o equilíbrio. Por fim, em 1920 (1996e) generaliza para as pessoas de forma geral:

A perda do amor e o fracasso deixam atrás de si um dano permanente à autoconsideração, sob forma de uma cicatriz narcisista, o que, em minha opinião . . . contribui mais do que qualquer outra coisa para o "sentimento de inferioridade", tão comum nos neuróticos (p. $30)$.

Se o investimento desde os primeiros anos é importante para a autoestima, a análise de Freud da biografia se faz coerente, na medida em que, como destaca, sua mãe deixou de investi-lo narcisicamente devido a deficiência. No entanto, Freud (1914/1996d) especifica que a autoestima também está relacionada ao ideal do eu, de suas possibilidades de realização. Por esta via, uma compreensão possível seria, por exemplo, a de Lawlor e Elliot (2012) em que, no contexto atual, permeado de imagens de corpos perfeitos, atléticos e saudáveis são internalizados pelas pessoas com deficiência. Assim como são internalizadas as noções históricas de que se tratam de pessoas dignas de pena, simpatia ou compulsão para ajudar, incidindo sobre a autoimagem. Nesta compreensão, seria possível dizer que todas as pessoas com deficiência possuem como ideal os corpos perfeitos e não os ter seria uma forma de não satisfazer seu ideal acarretando em sentimentos de inferioridade. Este é um modelo bastante comum na literatura e, inclusive, no imaginário popular. Entretanto, para que fosse válido seria preciso definir que a complexidade dos fenômenos do ideal de eu, eu ideal e o estádio do espelho fossem restritos ao modelo de ideal da mídia. Nossa proposta se alinha a fala de Brauer (1998):

Então é possível que subjetivamente o fato de ser deficiente físico represente algo para uma determinada pessoa, que isso tenha concorrido no estabelecimento de sua identificação, que ela tenha se identificado ao significante "deficiente" para além das dificuldades motoras que este problema físico lhe acarretou, que isto signifique ainda outras coisas para essa pessoa. Isso é possível, mas não necessário (p. 59).

Propomos que talvez o sentimento de inferioridade faça parte da rede de significantes associados à "deficiente", possa ser parte da roupagem com a qual se dá a identificação. Nos termos de Lacan (1949/1988b), o efeito de quando se assume esta imagem. 
Do ponto de vista das imagens atreladas a deficiência que circulam pelo social, se encontram os animais fantásticos como Saci-Pererê e Curupira (Amaral, 1994) e imagens fruto da história, de que a deficiência é um sofrimento obrigatório e um castigo (Livneh, 1982). Há assim um ideal de deficiência, de como é ser alguém com uma deficiência. Amiralian (1986) bem descreve esse fenômeno como o papel social da deficiência, o modo pelo qual estas pessoas assumem supostos padrões de comportamento que devem adotar em suas relações. Tomando este papel como um ideal, podemos citar Freud (1914/1996d), que considera seu surgimento na influência crítica dos pais, que o transmite pela voz, pelos educadores, pessoas do ambiente e a opinião pública, funcionando como um vigia do eu.

Retomando Lacan (1960-61/1992), lembramos que o eu ideal, imaginário, a aspiração, é engendrado pelo desejo do Outro. É o Outro quem fornece uma imagem a ser utilizada pelo sujeito em sua forma de representar. Forma essa balizada pelo ordenamento do ideal de eu, simbólico, atrelado as exigências da lei. Tem-se aqui a fórmula freudiana de como as falas dos pais, professores e o campo social formam modelos e imagens. Estas, presentes em formatos, contornos e figuras, assim como em regras, formas de funcionamento, tal como uma roupagem a ser utilizada, para se propor um termo alternativo para "papel social".

Ao mesmo tempo em que o ideal do eu é um ponto de alteridade a partir do qual o sujeito se constitui na sua singularidade, como sujeito do significante, o eu ideal é a imagem da qual o sujeito vai se servir para que se constitua tanto sua imagem corporal quanto a realidade - já que essa imagem será o paradigma de todas as formas de semelhança que vai aplicar aos objetos (Nova, 2005, p. 44).

Desta imagem do Outro se constitui a autoimagem e consequentemente o modo pela qual a realidade será vista. Assim, a roupagem fornece além de uma figura e uma configuração de funcionamento, uma forma de se posicionar frente ao mundo, visto que eu ideal e ideal de eu fornecem contornos ao desejo.

Acerca desta "configuração de funcionamento" pode-se dizer de um guia para os comportamentos, mas não apenas no modo de agir, mas também na forma de agir. Levin (1997) faz uma leitura do estádio do espelho enfatizando a questão da psicomotricidade que parece pertinente a esse ponto. No primeiro momento, tem-se o bebê olhando no espelho e fazendo um gesto. De início quem sustenta a criança na postura em que se encontra é a mãe, mas dada a identificação, há uma transformação postural: "A postura responde assim à imagem ou, em outras palavras, a representação guia a postura no advento da imagem inconsciente de corpo" (p. 92). Esta imagem inconsciente do corpo se funda em referência a imagem virtual, assim como traços de movimento se iniciam a partir da postura vista no espelho. No segundo momento, tem-se a fadiga tônico-postural. $\mathrm{O}$ bebê tenta se erguer, mas não consegue, visto que a sustentação de sua postura não está em seus músculos, mas em uma imagem. "A transformação psíquica implícita, via identificação, o fascínio pela imagem especular determina mudanças posturais e corporais que organizam a construção corporal a partir desta ligação significante efetuada a partir do espelho virtual da criança" (p. 95). Em um terceiro momento, dito silencioso, o movimento (esforço) se detém, tal como uma fotografia, a tensão tônico-postural permanece estática em um ponto de maior captura imaginária, transformando-se em uma imagem fundamente que posteriormente será apropriada em seu corpo como esquema corporal.

O operador é a imagem corporal que unifica ao mesmo tempo o sujeito - conformando o eu (narcisismo) - e as sensações proprioceptivas, interoceptivas, cenetésicas e cinetésicas, 
configurando o esquema corporal e postural de um sujeito. Esta seqüência dramatiza os avatares do encontro entre a Estrutura e o Desenvolvimento a partir do exercício da função postural. Deste modo o eixo tônico-postural passa do apoio simbólico pelo toque do Outro para o apoio simbólico da imagem do corpo (Levin, 1997, p. 96, grifos do autor).

As posturas geram representações, ainda que estas não possam ser vistas. Para se apropriar da postura aliena-se à imagem para recuperá-la como representação em forma de esquema postural. Ou seja, há o registro de uma imagem, de modo que evocá-la o permite configurar seu corpo em determinada postura. Por fim, no quarto momento, o bebê busca tocar, agarrar, brincar, algo que o desvie de sua imagem e o faça voltar para sua mãe, outorgando, deste modo, à imagem o status de projeção cinética captada no espelho. Então, ao mover-se move a si próprio e sua imagem, em um encontro mútuo (Levin, 1997).

Esta passagem esclarece de que modo a imagem virtual que serve de identificação para o eu também produz esquemas posturais específicos. Associam-se imagens e posturas e o resultado pode ser exemplificado por Schilder (1950/1980) que mostra como determinadas posturas estão ligadas a determinados sentimentos. Por exemplo, uma pessoa cabisbaixa pode ser vista como alguém que está triste, assim como alguém de fato triste pode se colocar em posturas mais recolhidas. $\mathrm{O}$ fato é que estão em jogo mecanismos de identificação a imagens, aos modos regulados pela lei fálica de se expressar.

Todo este percurso permite acrescentar ainda à nossa noção de roupagem que determinadas posturas também se fazem presentes neste contexto. Assim, podemos retornar à questão: quais as consequências de se assumir a imagem de "deficiente", de se utilizar desta para se representar ao Outro? Primeiramente, tratam-se de pessoas que escutam (e são supostas neste lugar) "ser deficientes", seja pelos pais com os diagnósticos desde os primeiros anos, profissionais e pessoas do cotidiano. Considerando-se aqui tanto os casos em que se preconiza a deficiência excluindo o sujeito quanto as formas mais genuínas de se relacionar que não podem escapar da noção de deficiência - visto que se trata de uma marca real no corpo biológico. Como dito, em sua rede significante, "deficiente" está associado a elementos negativos, como indica Goffman (1988), associado ao lugar de exclusão do social pela via do diferente. Se estas imagens permeiam e são oferecidas a estas pessoas, de uma forma ou outra estas podem se encontrar "vestindo a roupagem" de deficiente, assumindo sua imagem no nível do ser, adquirindo seu modo de agir, se relacionar e suas posturas específicas. E, vale comentar a partir de Brauer (1998), que a substituição dos termos "deficiente" por "especial" e seus derivados modificam pouco a situação do ponto de vista da marca. Ainda que se mude o termo, o sentido veiculado e sua função significante permanecem a mesma. Mais importante que o termo é a sua função no laço social.

Encontramos aqui uma outra compreensão para o sentimento de inadequação das pessoas com deficiência. Talvez seja possível propor que o ideal, em alguns casos, não perpasse o "ser aquele com o corpo perfeito", mas do contrário: um modelo de deficiência faria parte de seu ideal e se sentir inferior seria parte da realização deste ideal, sendo uma estrutura básica que ganhará diferentes sentidos para cada sujeito. Não como essência, mas como roupagem, tratar-se-ia de como o sujeito se vê sendo visto "deficiente". Indicamos com Lacan (196061/1992) a importância do olhar nestes processos, é do lugar de Outro (tesouro dos significantes) que a imagem de deficiente se coloca ao sujeito e por ele se vê, julgando e impelindo o eu a se formatar dentro dos ideais. Esta poderia ser uma chave clínica de leitura, mas que necessitaria de maiores estudos e verificações. 


\section{Considerações finais}

O objetivo deste trabalho foi discutir o sentimento de inadequação da pessoa com deficiência e seus efeitos. Discutiu-se sobre como se constroem imaginariamente modelos e como estes se relacionam com a imagem de si de cada um. A deficiência, por sua vez, se mostra aos olhos do Outro social como um estado alterado destes modelos, suscitando um estranhamento. Pontuou-se que sob o significante "deficiência" os sujeitos podem se ordenar no laço social no lugar de resto, visto que, desde os primeiros anos, poderia se engendrar este lugar para o pequeno sujeito - ainda que irá ocupá-lo de maneira singular, ou mesmo nem chegar a ocupá-lo, em um quadro autístico.

Deste modo, foi proposto que sujeitos com um quadro orgânico de deficiência, possam, junto as inúmeras possibilidades, se organizar frente ao Outro a partir deste lugar de "deficiente", se identificando a ele e agindo a partir dele. Destaca-se "inúmeras possibilidades", pois o que se levantou neste artigo pode ser válido para determinados casos enquanto para outros não. De todo modo, faz avançar uma situação clínica pouco compreendida, ainda que muito apontada. Bem como, oferece uma proposta alternativa ao modelo sociológico do preconceito que mais se ocupa de seus agentes do que de seus alvos.

A contribuição deste artigo se encontra na possibilidade de leitura clínica que permita desconstruir lugares e, o mais importante, valorize o sujeito, lá onde não é alcançado por suas identificações e ideais. Ademais, aponta para a complexidade da escuta sobre estes casos, para que se atente as leituras rápidas que consideram que todos sofrem da mesma forma ou mesmo que todos chegam a sofrer. Há uma diferença entre a identificação e o sofrimento. Assim como, neste sofrimento há um sujeito que se posiciona de forma singular e que goza da posição imaginária que ocupa. Sendo assim, pesquisas futuras, principalmente de cunho clínico poderão auxiliar na construção das proposições aqui apresentadas.

\section{Referências}

Amaral, L. A. (1995). A Hidra de Lerna. Deficiência: uma fragmentação de conceitos em percurso acidentado. In Conhecendo a deficiência (em companhia de Hércules) (pp. 41-55). São Paulo: Robe Editorial.

Amaral, L. A. (1998). Sobre crocodilos e avestruzes: falando de diferenças físicas, preconceitos e sua superação. In J. G. Aquino (Org). Diferenças e Preconceito na Escola: alternativas teóricas e práticas (pp. 11-30). São Paulo: Summus.

Amiralian, M. L. T. M. (1986). Psicologia do excepcional. São Paulo: EPU (Temas básicos de psicologia).

Brauer, J. F. (1998). O sujeito e a deficiência. Estilos da Clinica, 3(5), 56-62

Freud, S. (1996a). Três ensaios sobre a teoria da sexualidade. In Edição standard brasileira das obras psicológicas completas de Sigmund Freud (Vol. VII, pp. 121-252). Rio de Janeiro: Imago (Trabalho original publicado em 1905).

Freud, S. (1996b). Leonardo da Vinci e uma lembrança de sua infância. In Edição standard brasileira das obras psicológicas completas de Sigmund Freud (Vol. XI, pp. 73-142). Rio de Janeiro: Imago. (Texto original publicado em 1910). 
Freud, S. (1996c). Totem e tabu. In Edição standard brasileira das obras psicológicas completas de Sigmund Freud (Vol. XIII, pp. 13-168). Rio de Janeiro: Imago. (Trabalho original publicado em 1912-1913).

Freud, S. (1996d). Sobre o narcisismo: uma introdução. In Edição standard brasileira das obras psicológicas completas de Sigmund Freud (Vol. XIV, pp. 75-108). Rio de Janeiro: Imago. (Trabalho original publicado em 1914).

Freud, S. (1996e). Além do princípio de prazer. In Edição standard brasileira das obras psicológicas completas de Sigmund Freud (J. Salomão, trad.) (Vol. XVIII, p. 11-75). Rio de Janeiro: Imago. (Trabalho original publicado em 1920).

Freud, S. (1996f). O ego e o id. In Edição standard brasileira das obras psicológicas completas de Sigmund Freud (J. Salomão, trad.) (Vol. XIX, pp. 15-73). Rio de Janeiro: Imago (Trabalho original publicado em 1923).

Freud, S. (1996g). Conferência XXXI: A dissecção da personalidade psíquica. In Edição standard brasileira das obras psicológicas completas de Sigmund Freud (J. Salomão, trad.) (Vol. XXII, pp. 63-84). Rio de Janeiro: Imago. (Trabalho original publicado em 1932).

Freud, S. (2010). Observações psicanalíticas sobre um caso de paranóia [Dementia Paranoides] relatado em Autobiografia ("O Caso Schereber") (Obras completas, Vol. 10, pp. 13-107). São Paulo: Cia. das Letras. (Trabalho original publicado em 1911).

Gascón, M. R. P., Santos, R. F., Capitão, C. G., Fantine-Nogueira, M. C. \& Oliveira, A. C. P. (2013). Um corpo que perde o sentido: uma leitura psicanalítica dos pacientes com paraparesia espástica tropical. Revista da Sociedade Brasileira de Psicologia Hospitalar, 16, 1, 33-48.

Goffman, E. (1988). Estigma - notas sobre a identidade deteriorada. São Paulo: LTC.

Lacan, J. (1986). O seminário: Livro 1: Os escritos técnicos de Freud. Rio de Janeiro: Zahar (Trabalho original publicado em 1953-1954)

Lacan, J. (1992). O seminário, livro 8: a transferência. Rio de Janeiro: Zahar. (Trabalho original publicado em 1960-61).

Lacan, J. (1998a). A agressividade em psicanálise. In Escritos (pp. 104-126). Rio de Janeiro: Zahar. (Trabalho original publicado em 1948).

Lacan, J. (1998b). O estádio do espelho como formador da função do eu tal como nos é relevada na experiência psicanalítica. In Escritos (pp. 96-103). Rio de Janeiro: Zahar. (Trabalho original publicado em 1949).

Lacan, J. (1998c) Observação sobre o relatório de Daniel Lagache: "psicanálise e estrutura da personalidade". In Escritos (pp. 653-691). Rio de Janeiro: Zahar. (Trabalho original publicado em 1960).

Lacan, J. (2003). A identificação: seminário 1961-1962. Recife: Centro de estudos Freudianos do Recife. (Trabalho original publicado em 1961-1962).

Lawlor, M. C., \& Elliot, M. L. (2012). Physical Disability and Body Image in Children. In T. F. Cash (Ed.), Encyclopedia of Body Image and Human Appearance (Vol. 2, pp. 650-656). Los Angeles: Elsevier. doi:10.1016/B978-0-12-384925-0.00102-4

Levin, E. (1997). A infância em cena: constituição do sujeito e desenvolvimento psicomotor. Rio de Janeiro: Vozes.

Livneh, H. (1982). On the origins of negative attitudes toward people with disabilities. Rehabilitation Literature, 43(11-12), 338-347.

Nova, M. A. A. (2005). Como se faz corpo? Considerações sobre o ideal em Freud e Lacan. Pulsional, ano XVIII, 182, 40-47. 
Shields, N., Murdoch, A., Loy, Y., Dodd, K. J. \& Taylor, N. F. (2006). A systematic review of the self-concept of children with cerebral palsy compared with children without disability. Developmental Medicine and Child Neurology, 48(2), 151-157. doi:10.1017/s0012162206000326

Schilder, P. (1980). A imagem inconsciente do corpo. São Paulo: Martins Fonte (Trabalho original publicado em 1950).

Sit, C. H. P., Lau, C. H. L. \& Vertinsky, P. (2009). Physical Activity and Self-Perceptions Among Hong Kong Chinese With an Acquired Physical Disability. Adapted Physical Activity Quarterly, 26(4), 321-335.

Suc, N., Lesnik, B. \& Erpic, S. C. (2015). Differences in self-concept among persons with disabilities due to practicing adaptive alpine skiing. Kinesiologia Slovenica, 21(3), 34-42.

Taleporos, G. \& McCabe, M. P. (2002). Body image and physical disability - personal perspectives. Social Science \& Medicine, 54(6), 971-980. doi:10.1016/s0277-9536(01)00069-7

Tam, S. F., Chan, M. H., Lam, H. W. \& Lam, L. H. (2003). Comparing the self-concepts of Hong Kong Chinese adults with visible and not visible physical disability. Journal of Psychology, 137(4), 363-372.

Taylor, A. (2008). Examined life - philosophy in the streets. Documentário, 87 min. Canadá. Judith Butler \& Sunaura Taylor. Recuperado em nov, 2011 de www.youtube.com/watch?v=k0HZaPkF6qE.

Recebido em janeiro/2019 - Aceito em agosto/2019. 